\title{
Emotion Regulation and Service Organizational Citizenship Behaviors: Moderating Role of Gender
}

\author{
Syahrizal ${ }^{1}$, Ayu Wahdania ${ }^{2}$ \\ ${ }^{1}$ Dept. of Management, Faculty of Economics, Universitas Negeri Padang, Padang, Indonesia \\ $\triangle$ (e-mail) syahrizal.unp@gmail.com \\ ${ }^{2}$ Faculty of Economics, Universitas Negeri Padang, Padang, Indonesia
}

\begin{abstract}
The purpose of this study is to examine the direct effect of emotion regulation (deep acting and surface acting) on service-oriented organizational citizenship behavior (SO-OCB), and to test for the moderating effect of gender on the relationship between emotion regulation and SO-OCB. The subjects of this study were the frontline service employee at the four-star hotels in Padang, West Sumatera, including personnel at front desks, in service centers, in housekeeping, and in restaurants. For data analyses, a series of hierarchical moderated regression analyses with a method of sub group were employed. The study finds that deep acting and surface acting significantly affects SO-OCB. Gender moderated the relationship between deep acting and SO-OCB. Male moderated the relationship between surface acting and $\mathrm{SO}-\mathrm{OCB}$, but female did not moderate the relationship between surface acting and SO-OCB.
\end{abstract}

Keywords: deep acting, surface acting, gender, service-oriented organizational citizenship behavior.

\section{Introduction}

The key to the success of the hospitality industry in maintaining their competitive advantage is by providing satisfactory quality service to its customers. To achieve this, employees have an important role in fulfilling customer satisfaction. Attitudes and behavior of employees can have a significant effect on customer perceptions of the quality of service. Delivery of quality service requires that employees go beyond their job description to provide better service into meet or exceed customer expectations and, in turn, to build customer satisfaction (Ma \& Qu, 2011).

In building the best service quality is requires that employees go beyond their job description. Organizational citizenship behavior, a concept that describes an employee's willingness to exceed the requirements of his or her job description (Organ, 1988). By considering the flexible and constantly changing features of the service environment, Van Dyne, Graham, Dienesch (1994) developed the concept of service-oriented organizational citizenship behavior (SO-OCB) based on features common to the service industry. SO-OCB in the service industry not only benefits service delivery, provides higher quality service, and creates a friendlier environment that encourages customer interaction but also provides a service innovation view that fits customer demands more closely and creates higher customer satisfaction. Thus, the service industry must actively consider methods for SO-OCB from its employees to enhance service quality (Podsakoff, Whiting, Podsakoff, \& Blume, 2009).

Most organizations have implicit or explicit requirements concerning which emotions employees express and how and when they express them. These requirements are seen as more central in jobs that entail high levels of interaction with customers, such as customer service roles. Employees are expected to regulate their emotions. There are two emotion regulation namely deep acting and surface acting (Grandey, 2000). Deep acting involves attempting to modify actual feelings to match required displays. In contrast, surface acting involves attempting to modify affective displays without changing underlying feelings. Thus, with deep acting, the employee tries to genuinely feel 
the desired emotion; with surface acting, an employee manipulates or "fakes" the appropriate emotional display.

The majority of previous studies had focused on the relation between emotion regulation and occupational well-being as job outcomes (e.g., Grandey \& Groth, 2012; Lee \& Ok, 2012). However, the relation between emotion regulation and job performance, particularly contextual performance such as SO-OCB, has not been explored. We posit that emotion regulation model (Grandey \& Meloy, 2017) is a useful framework to examine the relation between emotion regulation and SO-OCB. We will also examine the moderating role of gender between emotion regulation and OCB under this theoretical framework.

In service settings, the extent to which an employee engages in surface and deep acting may influence whether they perform SO-OCB. Van Dyne et al (1994) developed three dimensions of SOOCB for employees serving customers: loyalty, service delivery, and participation. Loyalty means that employees actively promote an organization's products, services, and image to customers. Additionally, the perceptions of service industry employees can directly affect the perceptions of customers. Several studies on service quality have noted the importance of service industry employees displaying reliable, responsive, and polite behavior. Therefore, the second dimension is service delivery. Finally, service industry employees play the role of communication bridge between the external environment and internal operations. Service industry employees not only report customer demands but also provide suggestions for improving service. Thus, participation means the voluntary provision of suggestions for service improvement to satisfy the changing needs of customers (Bettencourt, Gwinner, \& Meuter, 2001). Many studies have adopted the three SO-OCB dimensions that Van Dyne et al. (1994) developed to measure the behavior of service industry employees. Van Dyne, Graham, and Dienesch studied the frontline employees of 100 companies in the service industry and via validity analysis found internal consistency of the three dimensions $(\alpha>$ 0.80). Thus, this study uses loyalty, service delivery, and participation to measure SO-OCB.

Emotion regulation is an emotional process-based approach to increase, maintain, or decrease one or more components of emotions (feelings, behavior, and physiological responses) (Gross, 1998). In a work environment, emotion regulation can be done with deep acting and surface acting (Grandey, 2000). Deep acting is way of modifying feelings to meet emotional display rules. Deep acting may enable employees to feel these positive emotions. Surface acting is a form of response focused emotion regulation is done when the emotion has grown by modifying the emotional expression. According to Grandey (2000), with surface acting, individuals may attempt to suppress unwanted feelings by simply faking appropriate displays. This evidence suggests that surface acting can be a productive strategy for managing negative emotions and engaging in effective interpersonal behavior (Grant, 2013).

According to Grandey and Melloy's (2017) model, OCB is an outcome of emotion regulation. When employees engage in emotion regulation, they are striving to increase, maintain, or decrease one or more components of an emotion (Côté, 2005). A fundamental tenet of theories of emotion is that individuals' behaviors are influenced by how they feel. In fact, employees who performed surface and deep acting more frequently were also more proactive for their organization (e.g., voice; Grant, 2013), suggesting either ER strategy can help employees support organizational goals.

Researchers have started to link emotion regulation to interpersonal performance with coworkers as well as customers. Deep acting was positively related to self-reported OCB toward coworkers, whereas those who tend to use surface acting engage in less OCB (Kiffin-Petersen et al. 2011). Halbesleben and Bowler (2007) suggested that, as an employee engage in surface acting, they may increase their performance of SO-OCB as a way to obtain social support. The benefits of helping colleagues, for example, may outweigh the energy expenditure. Salami (2007) found a positive relationship between deep acting and OCB in a study of public servants. Deep acting may engender a good mood at work because the person actively tries to feel the emotions that are needed (Johnson \& 
Spector, 2007). The enhanced psychological well-being associated with positive emotions may have a positive effect on employees' willingness to perform SO-OCB. Employees who deep act are also thought to have positive intentions towards the organization, suggesting they may also perform more discretionary behaviors (Grandey, 2000). Surface and deep acting may potentially act as predictors to SO-OCB in service settings.

Given the preceding arguments, we test the following hypotheses:

$\mathrm{H}_{1}$ Surface acting is positively related to SO-OCB

$\mathrm{H}_{2}$ Deep acting is positively related to SO-OCB

Making gender a natural individual difference to examine in concert with emotion regulation (Grandey \& Melloy, 2017). A relatively consistent finding in the emotions literature is that women are both expected to and do show greater emotional intensity and emotional expressiveness than men, and such differences hold for both positive and negative emotions (Brody \& Hall, 2008). The root of such differences may lie in role development, whereby females are socialized to be more emotionally expressive and men are socialized to be more emotionally restrained (Grossman \& Wood, 1993). Socialization pressures also influence the types of emotions that females and males are expected to express. Positive, relationship-facilitating emotions such as warmth and cheer are considered more role-appropriate for women than men, whereas negative, distancing emotions such as anger and hostility are viewed as more role-appropriate for men than women (Brody \& Hall, 2008). According to poststructuralist feminist theorists (e.g., Mumby \& Putnam, 1992), these expectations carry over into workplaces and are perpetuated by organizational norms and practices that construct different emotional roles for women and men.

These gender differences should have implications for the relationships emotion regulation and SO-OCB. Beginning with surface acting, when women attempt to mask or fake an emotion, they should experience greater emotional dissonance because their actions are at odds with their tendency to display and express what they are actually feeling. Men, however, should experience less emotional dissonance, because they are more accustomed to hiding emotions from others and faking affective states (Fabes \& Martin, 1991). Moreover, when display requirements call for the expression of positive emotion, the use of surface acting should be especially detrimental to women, because the persistence of an underlying negative affective state conflicts with gender role requirements to display positive emotion. Consistent with identity and dissonance perspectives, women were more distressed and dissatisfied by faking displays because being genuinely warm with others is congruent with gender identity norms for women (Scott \& Barnes 2011). Similarly, when surface acting was consistent with cultural values for social harmony (i.e., collectivistic cultures), it was less distressing than when performed by those who highly value individual expression (Allen et al., 2014)

In contrast to surface acting, deep acting should be more beneficial for females than males. In a customer service context, the cultivation of positive affective states via deep acting should not only be more role-appropriate for women than for men, but also, to the extent that women experience such states more intensely (Brody \& Hall, 2008), deep acting should yield a greater gain for women than for men. In addition, research has shown that women are more adept than men at producing "authentic" smiles implying that women are better at deep acting than men (Johnson \& Spector, 2007).

Drawing from this literature, we propose that gender moderates the relationships among emotion regulation and $\mathrm{SO}-\mathrm{OCB}$, as formulated as follows.

$\mathrm{H}_{3}$ Gender moderates the relationship between surface acting and SO-OCB

$\mathrm{H}_{4}$ Gender moderates the relationship between deep acting and SO-OCB 


\section{Methods}

According to statistics provided by the BPS, there are 7 four star hotels in Padang, West Sumatera. We contacting the senior managers of these hotels, and a total of 737 employee. Sampling using Slovin formula and obtained 259 respondents and the return of only 216 respondents. However, the final sample of this study was 184 respondents because there were respondents who did not complete the questionnaires.

Gender as a variable in this study was encoded, $1=$ male, $2=$ female. The surface acting and deep acting scales used in this study were developed by Diefendorff et al. (2005). The surface acting scale consisted of seven items, and the deep acting scale consisted of four items. The survey asked employees to indicate their agreement with a series of statements about how they respond to a statement $(1=$ "disagree strongly" and $5=$ "agree strongly"). A sample surface acting item was, "I fake the emotions I show when dealing with customers," and a sample deep acting item was, "I try to actually experience the emotions that I must show to customers".

SO-OCB scales used in this study were developed by Bettencourt et al. (2001). The SO-OCB consisted of three dimensions, namely, loyalty, service delivery, and participation with 16 items. The survey asked employees to indicate their agreement with a series of statements about how they respond to a statement $(1=$ "disagree strongly" and $5=$ "agree strongly"). A sample SO-OCB item was, "Tells outsiders this is a good place to work."

\section{Results and Discussion}

Before hypothesis testing, the study analyzed the data for the validity and reliability tests. Validity test was done by exploratory factor analysis for SO-OCB, surface acting, and deep acting. Reliability test was done by Cronbach's alpha. The classical assumption test was done to find out whether the data used meet the regression assumption. This test includes, test of normality, linearity, multicollinearity, and heteroscedasticity. Test results show that all assumptions are met.

Descriptive statistics, zero-order correlations, and coefficient alphas are reported in Table 1. Most of the correlations are consistent with expectations. Surface acting is positively associated with SOOCB $(r=0.213)$, deep acting is positively associated with SO-OCB $(r=0.02)$, and surface acting is positively associated with deep acting $(\mathrm{r}=0.230)$. All variables have alpha coefficients above 0.7 .

Table 1 Means, standard deviation, alpha coefficients, and correlations

\begin{tabular}{lccccc}
\hline Variable & Means & sd & alpha & 1 & 2 \\
\hline Surface & 3.52 & 1.18 & 0.863 & & \\
acting & & & & & \\
Deep acting & 4.09 & 0.88 & 0.757 & $0.230^{* *}$ & \\
SO-OCB & 4.19 & 0.72 & 0.809 & $0.213^{* *}$ & $0.302^{* *}$ \\
\hline
\end{tabular}

Note: $n=184$

$p^{*}<0.05$ (Two-tailed)

$p^{* *}<0.01$ (Two-tailed)

Hierarchical regression with sub-group was used to test the study's hypotheses. Hypothesis 1 and 2 predicted that surface acting and deep acting would be positively correlated with SO-OCB. Therefore, we regressed surface acting and deep acting on SO-OCB (see Table 2). Shown in step one of the regression models, the individual beta weights indicated both surface acting $(\beta=0.210 . p<$ $0.001)$ and deep acting $(\beta=0.639, p<0.001)$ positively correlated with SO-OCB. Thus, Hypotheses 1 and 2 were supported.

Hypotheses 3 stated that gender moderates the relationship between surface acting and SO-OCB. Shown in step two of the regression models, interaction between surface acting and male on SO-OCB $(\beta=0.269, \mathrm{p}<0.05)$, but female do not moderate the relationship between surface acting and SO-OCB. Thus hypotheses 3 were supported in regards to the male gender. 
Hypotheses 4 stated that gender moderates the relationship between deep acting and SO-OCB. The results show that hypotheses 4 were supported in regards to the male gender $(\beta=0.861, p<0.01)$ and female $(\beta=0.210, \mathrm{p}<0.05)$,

Table 2 The moderating effects of gender on SO-OCB

\begin{tabular}{lcccc}
\hline \multirow{1}{*}{ Independent Variable } & \multicolumn{4}{c}{ Dependent Variable: SO-OCB } \\
\cline { 2 - 5 } & $\beta$ & SE $\beta$ & Adj R $^{2}$ & $\Delta$ Adj R $^{2}$ \\
\hline Main Effects & & & 0.144 & \\
\hline Surface acting & $0.210^{* *}$ & 0.076 & & \\
\hline Deep Acting & $0.639^{* *}$ & 0.153 & \\
\hline Gender & $11.273^{*}$ & 5.253 & \\
\hline Moderating Effects & & & \\
\hline Sub-Group 1 & & & \\
\hline Surface Acting X Male & $0.269^{*}$ & 0.130 & $0.044^{* *}$ \\
\hline Deep Acting X Male & $0.861^{* *}$ & 0.240 & \\
\hline Sub-Group 2 & & & \\
\hline Surface Acting X Female & 0.065 & 0.047 & \\
\hline Deep Acting X Female & $0.210^{*}$ & 0.104 & \\
\hline $\begin{array}{l}\text { Note: } n=184 \\
p^{*}<0.05 \text { (Two-tailed) }\end{array}$ & & & \\
$p^{* *}<0.01$ (Two-tailed) & & &
\end{tabular}

Emotion regulations are seen as more central in jobs that entail high levels of interaction with customer. At the same time, SO-OCB of employee are essential for hotel operations. Using a sample of employees, we examined the association between emotion regulation and SO-OCB and tested the moderating role of gender in the relation. We found that emotion regulation, including deep acting and surface acting are significantly related to SO-OCB. Furthermore, we found that these relations are moderated by gender. Specifically, we found that Male and Female moderated the relationship between deep acting and SO-OCB. Male moderated the relationship between surface acting and SO$\mathrm{OCB}$, but Female did not moderate the relationship between surface acting and SO-OCB.

Based on emotion regulation literature, that one strategy was preferable to the other for both personal and organizational goals. This was a departure from the emotional labor ideas by Hochschild (1983), who suggested that engaging in either deep acting or surface acting was alienating to one's sense of self because one's emotions or expressions (respectively) become the organization's.

In emotion regulation contexts, positive emotional requirements are more congruent with social norms for women than men (Hochschild 1983), but evidence for gender differences in emotion regulation frequency are mixed (e.g., Johnson \& Spector 2007, Scott \& Barnes 2011). Based on this research, male tend to use surface acting and deep acting with customers. That is, they can manage their emotion in the workplace. Consequently, emotion regulation can trigger positive behavior, e.g. SO-OCB.

\section{Conclusions}

Emotion regulation is a key element in the service industry. Employees are expected to display positive emotions and regulate emotional expression to increase customer satisfaction. We found in this study that surface acting and deep acting are both significantly related to higher level of SO-OCB. Hotels may facilitate the use of surface acting and deep acting so that emotion regulation does not interfere with the positive work experience among employee. For example, employee can be trained to practice surface acting and deep acting when necessary. Totterdell and Parkinson (1999) showed that employee can benefit from mood regulation trainings focusing on practical skills such as behavioral diversion, attentional deployment, and cognitive reappraisal, which had been found to predict mood improvement. After training, employee can then apply these techniques to regulate 
their emotions while handling disruptive behaviors of pupils or other emotionally arousing situations. Training may also be provided to ensure the appropriate expression of naturally felt emotion among employee. Abilities to recognize the specific requirements of emotional expression in a situation and whether or not one's current mood matches those requirements will be helpful in deciding when to deploy the expression of naturally felt emotion. If this assessment about one's mood and its appropriateness for a situation can be made proficiently, employee can then better conserve their energy resources in different work situations.

In this study, our interpretation of the results was limited by the cross-sectional, self-report survey design. Future studies may be designed to include data from other sources (e.g., supervisors, coworkers, as external validation. Longitudinal design would be ideal for the examination of the sequential link between emotion regulation and SO-OCB. Future studies may also adopt experience sampling to address daily variations in one's use of emotion regulation and performance of SO-OCB at work.

\section{References}

Allen, J. A., Diefendorff, J. M., Ma Y. (2014). Differences in emotional labor across cultures: A comparison of Chinese and US service workers. Journal Business Psychology 29, 21-35

Bettencourt, L. A., Gwinner, K. P., \& Meuter, M. L. (2001). A comparison of attitude, personality, and knowledge predictors of service-oriented organizational citizenship behaviors. Journal of Applied Psychology, 86, 29-41.

Brody, L. R., \& Hall, J. A. (2008). Gender and emotion in context. In M. Lewis, J. M. Haviland-Jones, \& L. F. Barrett (Eds.), Handbook of emotions. New York: Guilfor.

Côté, S. (2005). A social interaction model of the effects of emotion regulation on work strain. Academy of Management Review, 30, 509 - 530.

Fabes, R. A., \& Martin, C. L. (1991). Gender and age stereotypes of emotionality. Personality and Social Psychology Bulletin, 17, 532-540.

Grandey, A. A. (2000). Emotional regulation in the workplace: A new way to conceptualize emotional labor. Journal of Occupational Health Psychology, 5, 95-110.

Grandey, A. A., \& Groth, M. (2012). Free to be you and me: A climate of authenticity alleviates burnout from emotional labor. Journal of Occupational Health Psychology, 17, 1-14.

Grandey, A. A., \& Melloy, R. C. (2017). The state of the heart: Emotional labor as emotion regulation reviewed and revised. Journal of Occupational Health Psychology, 22, 407-422.

Grant, A. M. (2013). Rocking the boat but keeping it steady: The role of emotion regulation in employee voice. Academy of Management Journal, 56(6),1703-1723.

Gross, J. J. (1998). The emerging field of emotion regulation: An integrative review. Review of General Psychology, 2, 271-299.

Grossman, M., \& Wood, W. (1993). Sex differences in intensity of emotional experience: A social role interpretation. Journal of Personality and Social Psychology, 65, 1010-1022.

Hochschild, A. (1983). The Managed Heart: Commercialization of Human Feeling. Berkley: University of California, Press.

Johnson, H. A. M., \& Spector, P. E. (2007). Service with a smile: Do emotional intelligence, gender, and autonomy moderate the emotional labor process? Journal of Occupational Health Psychology, 12, 319-333

Kiffin-Petersen S. A., Jordan C. L., Soutar, G. N. (2011). The Big Five, emotional exhaustion and citizenship behaviors in service settings: the mediating role of emotional labor. Personal. Individual Differences, 50, 43-48

Lee, J. J., \& Ok, C. (2012). Reducing burnout and enhancing job satisfaction: Critical role of hotel employees' emotional intelligence and emotional labor. International Journal of Hospitality Management, 31, 1101-1112. 
Ma, E., \& Qu, H. (2011). Social exchanges as motivators of hotel employees' organizational citizenship behavior: the proposition and application of a new three dimensional framework. International Journal of Hospitality Management, 30, 680-688.

Mumby, D. K., \& Putnam, L. L. (1992). The politics of emotion: A feminist reading of bounded emotionality. Academy of Management Review, 17, 465-486.

Organ, D. W. (1988). Organizational Citizenship Behavior: The Good Soldier Syndrome. Lexington, MA. Lexington Books.

Podsakoff, N. P., Whiting, S. W., Podsakoff, P. M., \& Blume, B. D. (2009). Individual and organizational- level consequences of organizational citizenship behaviors: a meta-analysis. Journal of Applied Psychology, 94(1): 122-141.

Salami, S. O. (2007). Moderating effect of emotional intelligence on the relationship between emotional labour and organizational citizenship behaviour. European Journal of Social Sciences, $5(2), 142-150$.

Scott BA, Barnes C. M. (2011). A multilevel field investigation of emotional labor, affect, work withdrawal, and gender. Academy of Management Journal. 54, 116-36.

Van Dyne, L., Graham, J. W., \& Dienesch, R. M. (1994). Organizational citizenship behavior: construct redefinition, measurement, and validation. Academy of Management Journal, 37, 765-802. 